\title{
Thinking Twice about the Evolution of Photosynthesis
}

\author{
Tanai Cardona \\ t.cardona@imperial.ac.uk \\ Department of Life Sciences, Imperial College London, London, UK
}

\begin{abstract}
Sam Granick opened his seminal 1957 paper titled Speculations on the Origins and Evolution of Photosynthesis with the assertion that there is a constant urge in human beings to seek beginnings (I concur). This urge has led to an incessant stream of speculative ideas and debates on the evolution of photosynthesis that started in the first half of the twentieth century and shows no signs of abating. Some of these speculative ideas have become common place, are taken as fact, but find little support. Here I review and scrutinise three widely accepted ideas that underpin the current study of the evolution of photosynthesis: firstly, that the photochemical reaction centres used in anoxygenic photosynthesis are more primitive than those in oxygenic photosynthesis; secondly, that the probability of acquiring photosynthesis via horizontal gene transfer is greater than the loss of photosynthesis; and thirdly, and most importantly, that the origin of anoxygenic photosynthesis predates the origin of oxygenic photosynthesis. I shall attempt to demonstrate that these three ideas are often grounded on incorrect assumptions built on more assumptions with no experimental nor observational support. I hope that this brief review will not only serve as cautionary tale, but also that it will open new avenues of research aimed at disentangling the complex evolution of photosynthesis and its impact on the early history of life and the planet.
\end{abstract}

\section{Keywords}

Photosynthesis, Photosystem, Water oxidation, Oxygenic, Anoxygenic, Reaction centre

\section{The study of the evolution of photosynthesis}

Anoxygenic photosynthesis predates the origin of oxygenic photosynthesis (Hohmann-Marriott and Blankenship 2011). After the emergence of the earliest forms of anoxygenic phototrophic bacteria, the capacity scattered across a few groups of bacteria via horizontal gene transfer (Raymond 2009, Fischer et al. 2016). Oxygenic photosynthesis originated in an ancestor of Cyanobacteria when an anoxygenic photosystem gave rise to a water-splitting photosystem (Cardona et al. 2015). These three basic premises currently underlie the study of the evolution of photosynthesis and would hardly make anyone raise a sceptic eyebrow.

Up for debate are the mechanisms by which Cyanobacteria obtained two distinct photochemical reaction centres linked in series, Photosystem I and Photosystem II, the hallmark of oxygenic photosynthesis. Was the origin of Photosystem I and Photosystem II triggered by a gene duplication event occurring before phototrophy scattered across the tree of life (Allen 2005, Mulkidjanian et al. 2006, Sousa et al. 2013)? Or were these distinct photosystems acquired via horizontal gene transfer from lineages of anoxygenic phototrophs into a non-photosynthetic ancestor of Cyanobacteria right before the Great Oxidation Event (GOE) (Shih et al. 2017, Soo et al. 2017)? We can therefore debate how long it took for anoxygenic photosynthesis to emerge after the origin of life, and how long it took for oxygenic photosynthesis to emerge after the origin of anoxygenic photosynthesis. We could also debate the identity of the earliest phototrophs, the oldest type of photosystem, and whether this ancestral photosystem used chlorophyll, bacteriochlorophyll, or a mix of both.

By 2007, when the discovery of phototrophic Acidobacteria was published by Bryant et al. (2007) all groups of phototrophs then known had been proposed as the innovators of phototrophy, a wide-range of bacterial cell fusion and horizontal gene transfer combinations had been suggested for the birth of Cyanobacteria, and almost every possible scenario for the nature of the earliest photochemical reaction centre had already been put forward. I reviewed this briefly in Cardona (2015), but see also Olson and 
Blankenship (2004). It is only proof that the study of the evolution of photosynthesis is fascinating, it exerts an almost irresistible force on the curious mind that marvels on the origin of things and drives us to speculate. I have not been able to resist this force despite my best efforts (Cardona 2016); I have certainly not been the first one (Granick 1957) and will certainly not be the last one (Martin et al. 2018).

This long history of speculation in the evolution of photosynthesis has blurred the line between what is assumed to be true and the facts as supported by rigorous evidence. In this essay I shall demonstrate that several core ideas in the study of the evolution of photosynthesis are based on unsupported-sometimes incorrect - assumptions. A comprehensive critical assessment of the molecular evolution of photosynthesis would require more space than I have here, for that reason I will only focus on these three basic premises: 1) That anoxygenic reaction centres are more "primitive" than those in oxygenic photosynthesis, 2) that the horizontal transfer of photosynthesis is more likely than the loss of photosynthesis, but above all 3) that anoxygenic photosynthesis predates oxygenic photosynthesis.

\section{Primitive photosynthesis}

It is widely believed that the photochemical reaction centres used in anoxygenic photosynthesis are more primitive than those used in oxygenic photosynthesis. Ten years ago, when I was still a PhD student and few years before I took the study of the evolution of photosynthesis as my full-time job, I came across an analogy that left me flabbergasted: that the anoxygenic Type II reaction centre of phototrophic Proteobacteria and Chloroflexi is like a Ford Model T car and in comparison Photosystem II, the wateroxidising enzyme, is like a Formula 1 racing car, implying that the former gave rise to the latter (Swingley et al. 2008). The logic behind this premise goes like this: "Water oxidation to oxygen is a difficult chemical reaction that requires great complexity. Photosystem II is more complex than anoxygenic Type II reaction centres; so surely, the anoxygenic reaction centre is more primitive and must have given rise to the oxygenic one."

This assumption is not new and its roots can be traced back to speculative commentary emerging from the early comparative biochemistry of anoxygenic and oxygenic photosynthesis, starting more than eighty years ago (Blum 1937, van Niel 1949, Arnon et al. 1958). For example, Blum (1937) reasoned that because oxygenic photosynthesis used four quanta of light to complete a catalytic reaction, unlike anoxygenic photosynthesis, the latter must have been more primitive. Then, this idea was later reworked, cemented, and popularised by Olson (1970), whose insight into the evolution of photosynthesis is as influential today as it was back then (Blankenship et al. 2018). It should be noted that this idea became popular well before we had a comprehensive understanding of the photosynthetic processes and long before we had access to sequences or structures of the reaction centres to put it to the test. Now this assumption has taken the appearance of almost undisputable fact.

While at first glance it seems quite reasonable, the flaw is found in the incorrect presupposition that the complexity of oxygenic photosynthesis, and by extension of Photosystem II, evolved before the origin of water oxidation photochemistry. Perhaps it is not too counterintuitively to think that the origin of water oxidation should be considered the trigger that led to an increase in complexity, because the increased complexity exists for the sole purpose of supporting water oxidation. After the origin of water oxidation greater complexity was evolved to make catalysis more robust and efficient (Cardona et al. 2012, Vinyard and Brudvig 2017), to incorporate protection mechanisms against the formation of reactive oxygen species and to diminish the risk of damage (Cser and Vass 2007, Brinkert et al. 2016). Increased damage caused by reactive oxygen species led to the evolution of a more complex repair and assembly process (Nixon et al. 2010, Nickelsen and Rengstl 2013). An increase in structural and functional complexity also led to the evolution of a more sophisticated regulatory processes acting from picoseconds to weeks and ranging from fine-tuning of electron transfer (Rutherford et al. 2012, Sugiura et al. 2013, Nurnberg et al. 2018) to longterm chromatic adaptation (Ho et al. 2017). The bottom line is that an apparent lack of complexity is not a definitive measure of primitiveness, yet that apparent complexity of Photosystem II disappears when the core reaction centre proteins are compared against each other (Figure 1 and 2).

The assumption that anoxygenic reaction centres are more primitive than those used in oxygenic photosystems is not supported by phylogenetic and structural evidence (Beanland 1990, Cardona 2015). Of note is the fact that the heterodimeric core of Photosystem II, made up of D1 and D2, originated from an unambiguous gene duplication event distinct to that which led to the heterodimeric core of the anoxygenic Type II reaction centres, made of L and M (Cardona 2015). The reason why this is unambiguous lies in the 
fact that D1 and D2 share much greater sequence and structural identity with each other than with L and M; and vice versa. While all Type II reaction centre proteins share common ancestry, the known anoxygenic Type II reaction centres are not direct ancestors of Photosystem II. They cannot be described as more primitive and they do not make any better models for what ancestral photosystems looked like than Photosystem II. The assumption that the ancestral Type II reaction centre before L, M, D1, and D2, was more like those found in Proteobacteria and Chloroflexi than those in Cyanobacteria, carries an entire load of unproven presuppositions: for example, that $\mathrm{L}$ and $\mathrm{M}$ retained more ancestral traits than D1 and D2, or that $\mathrm{L}$ and $\mathrm{M}$ are evolving at a significantly slower rate than D1 and D2.

The case for Type I reaction centres is similar. Anoxygenic Type I reaction centres are homodimeric, while Photosystem I in oxygenic photosynthesis is heterodimeric. Undoubtedly, the homodimeric state is the ancestral state, but that does not necessarily imply that Photosystem I in oxygenic photosynthesis directly originated from the reaction centre of any of the known groups of anoxygenic phototrophs. The phylogeny of Type I reaction centres indicates that all anoxygenic Type I homodimers share a more recent common ancestor to the exclusion of Photosystem I core subunits (Cardona 2015), which is also a reflection of the greater sequence and structural identity among homodimeric Type I reaction centres (Orf et al. 2018). It is indeed correct to say that a heterodimeric core is a novel trait relative to the ancestral state, but it would be incorrect to say that PshA or PscA, the reaction centre core subunits of phototrophic Firmicutes, Chlorobi and Acidobacteria, gave rise to the ancestral core subunit of cyanobacterial Photosystem I.

Cardona et al. (2018) recently showed that the core subunits of the anoxygenic Type II reaction centres are evolving on average about five times faster than the core subunits of the water-oxidising enzyme. They have likely done so for most of their evolutionary history. That D1 and D2 are evolving significantly slower has two major implications: 1) that the duplication of the oxygenic core that led to D1 and D2 is older than the duplication that led to L and M; and 2) that Photosystem II has retained more ancestral traits than its anoxygenic cousin. This is clearly seen in the structures of the photosystems, as Photosystem II not only has retained greater sequence and structural symmetry at the core, but also greater structural identity with Type I reaction centres (Figure 1 and 2). In a manner similar to Type II reaction centres, by studying the rates of evolution I have also found that the gene duplication leading to the heterodimeric core of cyanobacterial Photosystem I has a pretty good chance to have occurred before the diversification event leading to the different groups of phototrophs with homodimeric Type I reaction centres known today (Cardona 2018).

In consequence, the assumption that anoxygenic reaction centres are more primitive than those used in oxygenic photosynthesis is, at best, unsupported by their molecular evolution; at worst, incorrect.

\section{Easy transfer}

Arguably there is no topic more controversial in the study of the evolution of photosynthesis than whether the scattered distribution of phototrophy in the tree of life is largely due to widespread horizontal gene transfer or losses. But why is this important? If horizontal transfer of photosynthesis is a relatively easy process, then one could argue that oxygenic photosynthesis could have emerged at a late stage in the evolutionary history of life from the transfer of anoxygenic photosynthesis into a non-photosynthetic ancestor of Cyanobacteria, for example. If, on the other hand, the transfer of photosynthesis is a more difficult process then it may be more likely that the emergence of two distinct photosystems was the result of a gene duplication event, which occurred in a deep but direct ancestor of Cyanobacteria. Certainly, gains and losses of photosynthesis across geological time are not mutually exclusive and there is evidence that both have occurred.

This leads to the next popular assumption in the study of the evolution of photosynthesis: the idea that the probability of a non-photosynthetic organism gaining photosynthesis via horizontal gene transfer is greater than that of a photosynthetic organism losing photosynthesis. Given this assumption, if a clade of photosynthetic bacteria shares a more recent common ancestor with a non-photosynthetic clade, it is assumed that the ancestral state is more likely to be non-photosynthetic (Raymond 2009, Fischer et al. 2016). The recent discovery of early-branching non-photosynthetic Cyanobacteria, the Melainabacteria (Soo et al. 2014) and the Sericytochromatia (Soo et al. 2017), has lent credence to the hypothesis that oxygenic photosynthesis was invented after horizontal transfer of anoxygenic photosynthesis. This hypothesis relies on the assumption that the ancestral state was non-photosynthetic. 

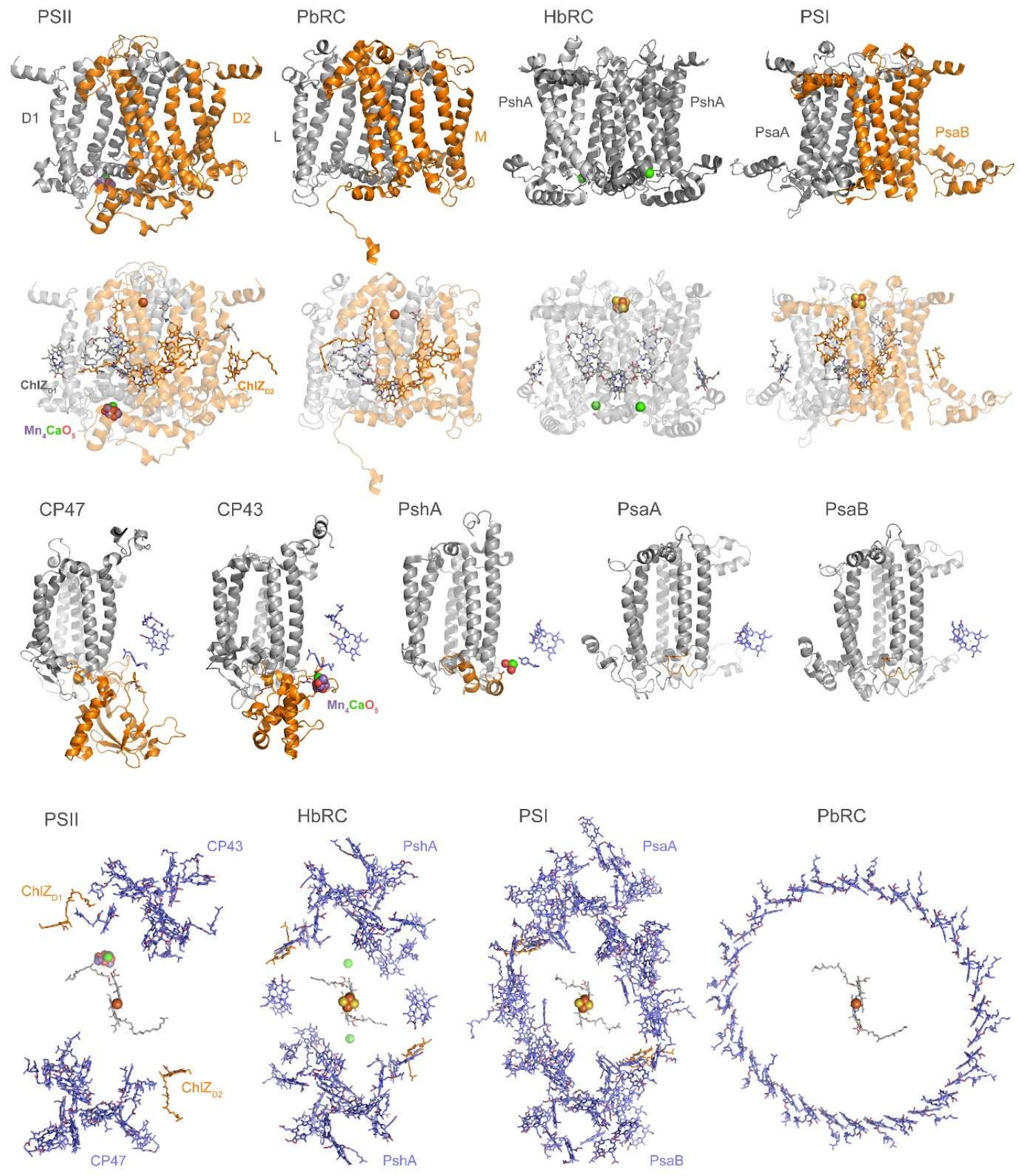

Figure 1. Structural comparisons. Top row, the reaction centre core subunits. PSII stands for cyanobacterial Photosystem II, $\mathrm{PbRC}$ for proteobacterial reaction centre, $\mathrm{HbRC}$ for heliobacterial reaction centre, and PSI for cyanobacterial Photosystem I. Which one of these structures is the most primitive? Second row, the core subunits are shown transparently to highlight the photochemical pigments. Type II reaction centres are characterised by a quinone/non-heme $\mathrm{Fe}^{2+}$ /quinone electron acceptor system. Type I reaction centres are characterised by a $\mathrm{Fe}_{4} \mathrm{~S}_{4}$ cluster as a terminal electron acceptor. ChlZ $\mathrm{Z}_{\mathrm{D} 1}$ and $\mathrm{Ch} 1 \mathrm{Z}_{\mathrm{D} 2}$ are a pair of peripheral chlorophylls bound to the core, but functionally associated with the antenna domain. These are conserved in PSII and other Type I reaction centres and are absent in anoxygenic Type II. Third row, the antenna domains: CP43 and CP47 are the antenna of PSII, PshA of the HbRC, and PsaA/PsaB of PSI. In Type I reaction centres the core and the antenna make a single protein. In PSII, the core and the antenna are separate proteins. Anoxygenic Type II reaction centres (PbRC) lack antenna domains, but have independently evolved a new light-harvesting complex. The $\mathrm{Mn}_{4} \mathrm{CaO}_{5}$ cluster is bound by $\mathrm{D} 1$ and $\mathrm{CP} 43$. In the $\mathrm{HbRC}$, a Ca is found at a similar position and it is bound by the core and the antenna like in PSII. Bottom row, a global top view of all the (bacterio)chlorophyll light-harvesting pigments. ChlZ $\mathrm{D}_{\mathrm{D} 1}$ and $\mathrm{Chl}_{\mathrm{D} 2}$, and their equivalent in Type I reaction centres, are shown in orange. The other antenna pigments are shown in blue. PDB ID: PSII, 3wu2; PbRC, 5y5s; HbRC, 5v8k; PSI, 1jb0. 


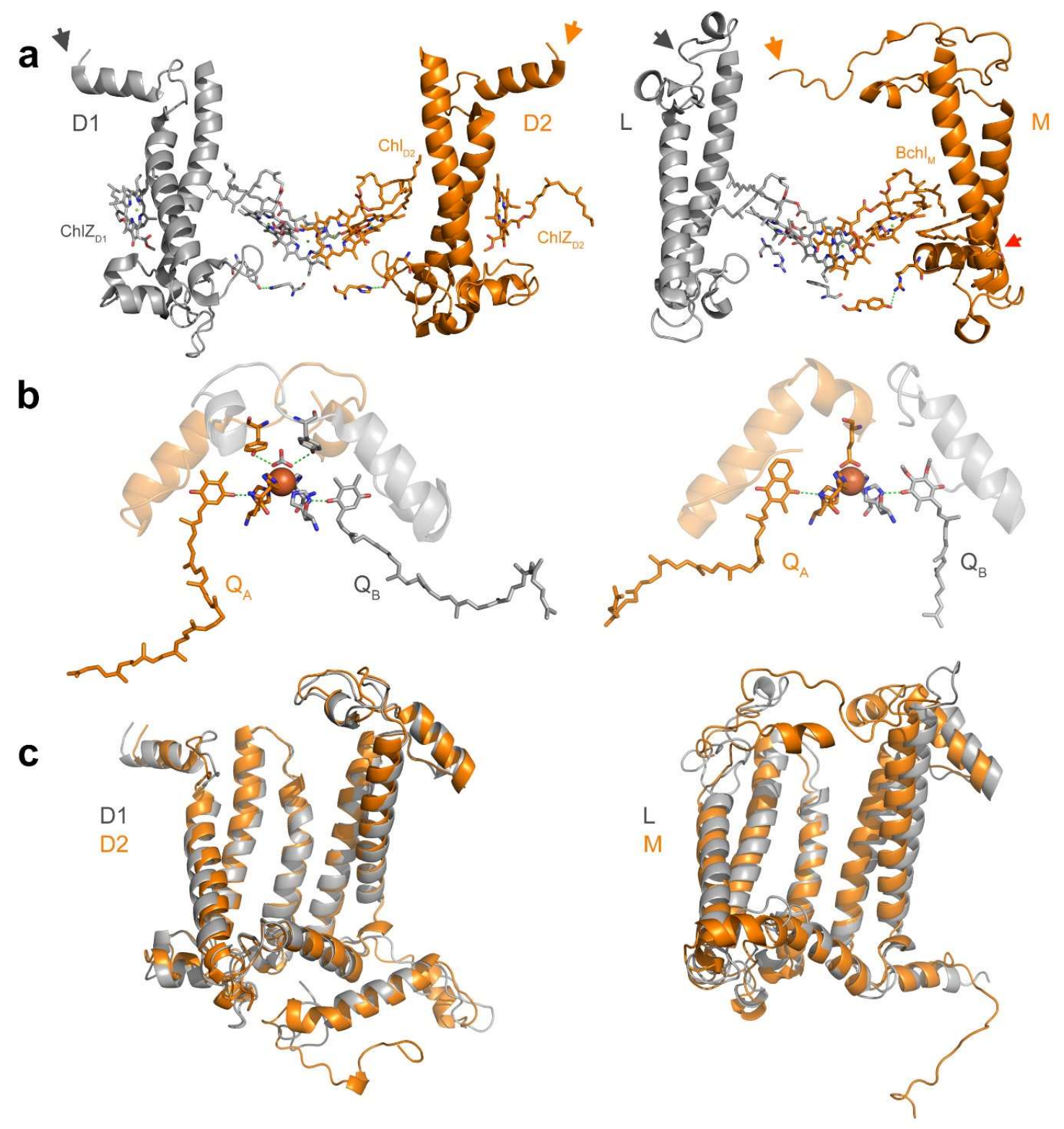

Figure 2. Heterodimerisation of Type II reaction centres. The core of Photosystem II has retained substantially more symmetry than anoxygenic Type II reaction centres. (a) A comparison of some structural elements between Photosystem II and the proteobacterial anoxygenic Type II reaction centre (PbRC). Only the first two transmembrane helices of the core subunits are shown. The $\mathrm{N}$-terminus is marked with a grey and an orange arrow: there is noticeably more symmetry at the $\mathrm{N}$ terminus between D1 and D2 than between $\mathrm{L}$ and $\mathrm{M}$. In the PbRC, the bacteriochlorophyll peripheral pigment Bchl M interacts with an asymmetrically located carotenoid. This is not found in the reaction centre of the Chloroflexi, instead a "third" pheophytin takes the position of Bchl $\mathrm{M}_{\mathrm{M}}$ conserving the pigment asymmetry. In Photosystem II strictly conserved redox active Tyr-His pairs are found on D1 and D2 at the donor side. In the PbRC an Arg takes the position of Tyr. In M, R164 provides a hydrogen-bond to Y193, which is substituted by Phe in the L subunit. (b) A comparison of symmetry at the quinone/nonheme $\mathrm{Fe}^{2+}$ /quinone electron acceptor system. In Photosystem II the non-heme $\mathrm{Fe}^{2+}$ is coordinated by bicarbonate, which is symmetrically bound by strictly conserved Tyr residues. In the PbRC, the non-heme $\mathrm{Fe}^{2+}$ is coordinated by a Glu residue in the $\mathrm{M}$ subunit showing that the PbRC electron acceptor side cannot have retained the ancestral state. (c) Overlap of D1 and D2 (left), and L and M (right). The root-mean-square deviation of atomic positions (RMSD) is a measurement of average distance between overlapped atoms of the backbone's alpha carbons. Between D1 and D2 the RMSD is $2.32 \AA$ over 320 residues, while between $\mathrm{L}$ and $\mathrm{M}$ is $4.37 \AA$ over 232 residues. The greater the symmetry, the better the overlap and the smaller the RMSD over a greater number of residues. 


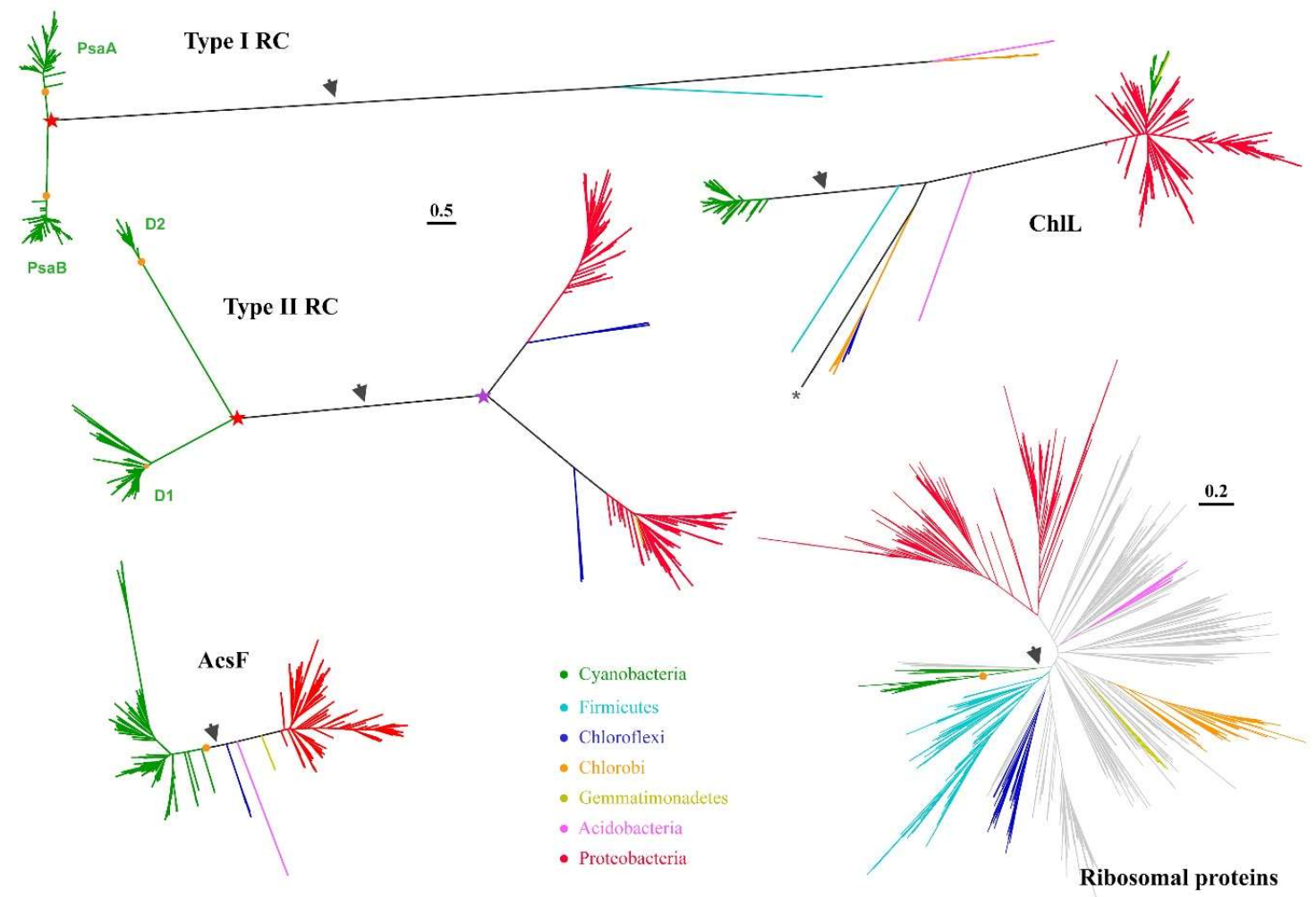

Figure 3. Losses of photosynthesis or horizontal gene transfer? Maximum Likelihood trees of Type I reaction centre proteins, Type II reaction centre proteins, protochlorophyllide reductase subunit L (ChlL), oxygen-dependent Mg-protoporphyrin IX monomethyl ester cyclase (AcsF), and a tree of concatenated ribosomal proteins reported by Hug et al (2016). The different phototrophic clades are coloured at phylum level. The topology of the trees of photosynthetic components matches closely the tree of ribosomal proteins subtracting non-phototorphic clades and accounting for duplication events (stars). The grey arrow represents the position of the root of the tree as calculated by Hug et al (2016). The orange circle marks the most recent common ancestor of Cyanobacteria capable of oxygenic photosynthesis (Oxyphotobacteria). The duplications leading to PsaA and PsaB, and to D1 and D2 are highlighted with a red star, and these duplications must predate the diversification of described Cyanobacteria. Similarly, the duplication leading to L and M (purple star) must predate the origin of phototrophic Chloroflexi and Proteobacteria. If the topology proposed by Hug et al (2016) is true only a single gain of photosynthesis via horizontal gene transfer is needed to explain the distribution of phototrophy: that of phototrophic Gemmatimonadetes. Exchange of proteins for the synthesis of chlorophyll via horizontal gene transfer can be noted, in particular a singular acquisition of protochlorophyllide reductase by a subgroup of Cyanobacteria, and a swap of the same enzyme between stem group Chlorobi and Chloroflexi. The asterisk marks a ChlL subunit from an uncharacterised group of phototrophs. Scale bar represents substitutions per site. All photosynthesis proteins are plotted at the same scale.

To the best of my knowledge there are no published studies that have attempted to determine the likelihood of gain $v s$ loss of photosynthesis across the tree of life.

There is only one case of a group of non-photosynthetic bacteria obtaining photosynthesis via horizontal gene transfer. That is the phototrophic Gemmatimonadetes. Zeng et al. (2014) demonstrated that this peculiar group of bacteria obtained a photosynthesis gene cluster from a gammaproteobacterium. Any other case of potential gains of photosynthesis in bacteria are ambiguous. The other (more spectacular) case of gain of photosynthesis are the photosynthetic eukaryotes. Horizontal gene transfer occurred from a cyanobacterium endosymbiont into the host nuclear genome of a non-photosynthetic unicellular eukaryote (Allen 2003, Gould et al. 2008). Nevertheless, after more than a billion years of evolution and the transfer of hundreds, if not thousands (Martin et al. 2002), of cyanobacterial genes into the eukaryotic nuclear genome, the core subunits of the photosystems have remained encoded in the plastid genome.

There are many clear cases of horizontal gene transfer of photosynthesis components between phototorphs. Several studies have shown for example that the marine Synechococcus and Prochlorococcus strains obtained protochlorophyllide reductase from gammaproteobacteria (Bryant and Liu 2013, Sousa et 
al. 2013). Their genes are distinctly and undoubtedly proteobacterial as they cluster specifically within Proteobacteria. Another peculiar case is the transfer of protochlorophyllide and chlorophyllide reductases between a stem-group phototrophic Chlorobi and a stem-group phototrophic Chloroflexi (Bryant et al. 2012), but the direction of transfer is ambiguous.

Recently it was suggested that not only Cyanobacteria obtained photosynthesis via horizontal gene transfer, but also Shih et al. (2017) and Ward et al. (2018) have made a compelling case for phototrophic Chloroflexi having evolved via the transfer of photosynthesis as early as $\sim 900$ million years ago. Gisriel et al. (2017) also proposed that Heliobacteria, the only known phototrophic Firmicutes, also obtained phototrophy via horizontal transfer justified by the presence of a photosynthesis gene cluster. What Shih et al. (2017) and Ward et al. (2018) did not discuss is that Cyanobacteria and Chloroflexi show phylogenetic affinity in many phylogenomic analyses appearing in many instances as each other's closest relatives (Ciccarelli et al. 2006, Jun et al. 2010, David and Alm 2011, Segata et al. 2013, Marin et al. 2017). One has reasons to argue that the most recent common ancestor ( $m r c a$ ) of these two phyla had Type II reaction centres. Indeed, the large phylogenetic distance between the core subunits of the anoxygenic Type II reaction centre and Photosystem II would be consistent with such a scenario. Similar kind of reasoning can be presented against the hypothesis that Heliobacteria obtained phototrophy via horizontal gene transfer. For example, Mix et al. (2005) noted that the evolution of Type I reaction centres is consistent with vertical descent, and if recent phylogenomic trees of prokaryotes have any resemblance to reality only a single gain of horizontal gene transfer of photosynthesis between phyla of bacteria can be identified (Hug et al. 2016): phototrophic Gemmatimonadetes, the exception that proves the rule (Figure 3).

An often-cited piece of evidence in favour of horizontal gene transfer scenarios is the fact that in some anoxygenic phototrophs most of the genes required to support phototrophy are encoded in a single gene cluster. Recently, Brinkmann et al. (2018) showed that within the family Rhodospirilaceae of Alphaproteobacteria the transfer of complete photosynthesis gene clusters have occurred. The authors calculated that even in the most stringent scenarios at least seven transfer events and eight losses events were needed to reconcile the species tree with the tree of the gene cluster. If these numbers are accurate that would make the chance of losses slightly more probable than gains, at least within the Rhodospirilaceae. However, from these seven transfers at least five can be better described as replacements of a native gene cluster with that from a closely related strain rather than true de novo gains of phototrophy, making the probability of losses substantially greater than gains. Furthermore, it could be argued than the greater the phylogenetic distance between the donor and the recipient strain, the less likely it will be that a nonphototroph will successfully integrate and express an entire photosynthesis gene cluster. We can now wonder if the reason why phototrophic Gemmatimonadetes managed to successfully integrate a photosynthesis gene cluster from Proteobacteria is because the phylum may have been ancestrally phototrophic to begin with, given that Gemmatimonadetes and Chlorobi show strong phylogenetic affinity (Segata et al. 2013, Hug et al. 2016). With the transfer representing exchange rather than gain. This seems unlikely if one is biased towards thinking that lack of photosynthesis is a more plausible ancestral state.

Perhaps more illustrative are the losses of oxygenic photosynthesis in Cyanobacteria and photosynthetic eukaryotes. One fascinating case is the loss of all Photosystem II-encoding genes in Atelocyanobacterium thalassa, along with the loss of roughly $75 \%$ of the original genome content (Thompson et al. 2012) in only 100 million years (Cornejo-Castillo et al. 2016). Another interesting case of loss of photosystem genes is that of the cyanobacterium endosymbiont of rhopalodiacean diatoms (Nakayama et al. 2014). In photosynthetic eukaryotes we find the well-known case of parasitic apicomplexa (Moore et al. 2008), multiple losses in dinoflagellates (Saldarriaga et al. 2001), chrysophytes (Grossmann et al. 2016), freeliving green algae (Smith and Lee 2014, Suzuki et al. 2018), and holoparasitic angiosperms (Ravin et al. 2016), among probably many others. Within flowering plants, about ten independent losses of photosynthetic capacity have already been documented (Westwood et al. 2010). One could argue that it is much more likely to lose a single anoxygenic photosynthesis gene cluster than to lose the entire complexity of oxygenic photosynthesis.

Not a single case of horizontal gene transfer of oxygenic photosynthesis between bacteria has been documented. Unlike anoxygenic photosynthesis, the numerous genes now required to support oxygenic photosynthesis are scattered across the cyanobacterial genomes (Mulkidjanian et al. 2006) making the probability of a non-photosynthetic bacterium acquiring oxygenic photosynthesis via horizontal gene transfer nil. In contrast and as we saw in the previous paragraph, the probability of loss of oxygenic 
photosynthesis is certainly above cero and can occur within less than 100 million years. Therefore, if the probability of loss of photosynthesis is just slightly greater than gain, it is expected that over billions of years the number of lineages of anoxygenic and in particular, of oxygenic phototrophs, have decreased. This not only explains the scattered distribution of photosynthesis in bacteria, but also the large phylogenetic distance between phototrophic lineages, a distance that is matched by that of their photosynthetic machinery (Figure 3): an aspect that is usually overlooked and unaccounted for in horizontal gene transfer scenarios.

This line of thought reveals another assumption on the study of the evolution of photosynthesis not based on any piece of scientific evidence, but nonetheless taken for granted: that Cyanobacteria are the only group of bacteria alive today to have descended from oxygenic phototrophs. In fact, it takes a very simple mental exercise to demonstrate that most of diversity of oxygenic phototrophs that have existed in the history of the planet likely predates the $m r c a$ of Cyanobacteria.

All Cyanobacteria share an mrca that was capable of oxygenic photosynthesis (Cardona et al. 2015) in the same way that birds originated from an mrca that had already evolved feathers (Sereno 1999, Xu et al. 2009). All Cyanobacteria share an mrca that had already evolved Photosystem I with a heterodimeric core. This is a trait that has been retained by all oxygenic phototrophs. A heterodimeric Photosystem I is a distinctive and exclusive characteristic of oxygenic photosynthesis and it is widely accepted that the heterodimerisation of the core was an adaptation to oxygenic photosynthesis (Ben-Shem et al. 2004, Hohmann-Marriott and Blankenship 2008, Rutherford et al. 2012). PsaA and PsaB, the core subunits of Photosystem I share about $43 \%$ sequence identity: this is true across the entire diversity of oxygenic phototrophs from the earliest branching Cyanobacteria to the most exotic variety of avocado, which implies that the mrca of Cyanobacteria inherited a heterodimeric Photosystem I that had PsaA and PsaB with about $43 \%$ identity. In other words, at the time of the mrca of Cyanobacteria, PsaA and PsaB had already changed by $57 \%$. If we compare the change of sequence identity of PsaA across all oxygenic phototrophs, the maximum level of change is not greater than about $30 \%$, and between all photosynthetic eukaryotes not greater than $20 \%$. It is exactly the same for PsaB. Therefore, most of the sequence change of the core subunits of Photosystem I occurred between the time of the duplication leading to PsaA and PsaB and the mrca of Cyanobacteria (Cardona 2018). Given that the rates of evolution of complex molecular systems is slow relative to speciation rates (Shi et al. 2005), that distance between PsaA and PsaB, that amount of change, must have been matched by a substantial biodiversity.

Such simple exercise exposes the inherent naivety of every proposed evolutionary scenario for the evolution of photosynthesis (including my very own), since it is impossible not to severely underestimate the biodiversity of anoxygenic and oxygenic phototrophic bacteria that have existed through geological time (Louca et al. 2018). Our best scenarios for the origin and diversification of photosynthesis are like trying to predict the size of a mountain from the shape of a leave of grass. With all of this in mind and based on the current state of knowledge, the assumption that the probability of gains of photosynthesis via horizontal transfer is greater than that of losses is far from proven, and might just as well not stand up to scrutiny.

\section{Let there be light}

The chief unproven assumption in the evolution of photosynthesis is that the origin of anoxygenic photosynthesis predates the origin of oxygenic photosynthesis. This assumption can be understood at two fundamental levels: 1) that oxygenic phototrophs evolved from anoxygenic phototrophs or 2) that Photosystem II evolved from an anoxygenic photosystem. The first fundamental level leads to the obvious question of when Cyanobacteria originated, but the question itself is problematic. Only one point in time in the evolution of oxygenic photosynthesis can be clearly defined and accessed through phylogenies of species trees: that is, the mrca of Cyanobacteria (Figure 4). A broad range of ages for this ancestor have been provided using molecular clocks ranging from 1.5 to 3.5 billion years (Falcon et al. 2010, SanchezBaracaldo et al. 2017, Shih et al. 2017, Betts et al. 2018, Magnabosco et al. 2018). Yet, in the same way that determining when the mrca of birds occurred cannot tell us when or how feathers originated, determining when the mrca of Cyanobacteria occurred cannot tell us when or how photochemical water oxidation to oxygen originated. And, in the same way that having feathers does not make Velociraptor a bird, there is a very real possibility that the origin of photochemical water oxidation to oxygen does not necessary falls in a lineage that was the immediate ancestor of the known diversity of Cyanobacteria.

A more precise line of enquiry is to determine for how long water oxidation existed before the mrca of Cyanobacteria. Contrary to what it may appear at a first glance, the answer to this question does not depend 
on the exact timing of the mrca of Cyanobacteria or whether this ancestor existed before or after the GOE, but instead it is strongly linked to when the earliest stages in the evolution of Photosystem II occurred. For example, the duplication leading to the alpha and beta subunit of ATP synthase is known to have occurred before the last universal common ancestor (LUCA) (Gogarten et al. 1989, Ouzounis et al. 2006, Mulkidjanian et al. 2007). It follows then that the initial stages in the evolution of ATP synthases is in no way dependent on the time of origin of any particular group of prokaryotes (e.g. Cyanobacteria, Firmicutes, Asgardarchaeota, Euryarchaeota), but it only depends on the molecular events at play during the emergence of the protein complex itself, including the duplication leading to the alpha and beta subunits: an event that predates the divergence of the domains Bacteria and Archaea, and the divergence of F-type and V-type ATP synthases.

So is the case for oxygenic photosynthesis (Figure 4). The two duplication events, which resulted in the evolution of a heterodimeric Photosystem II, one leading to D1 and D2 and the other to the core antenna subunits, CP43 and CP47, are much more likely to have occurred soon after the origin of the earliest reaction centres than right before the mrca of Cyanobacteria (Cardona 2018, Cardona et al. 2018). These two duplications together with the duplication leading to the core of Photosystem I are, to the best of our knowledge, exclusive to oxygenic photosynthesis (Rutherford et al. 1996, Rutherford and Nitschke 1996, Rutherford and Faller 2003). It was suggested before based on conserved symmetrical structural and functional characteristics of Photosystem II that water oxidation started before the duplication leading to heterodimerisation (Rutherford and Nitschke 1996, Rutherford and Faller 2003, Cardona et al. 2018). Cardona et al. (2018) recently calculated that the span of time between the duplication leading to D1 and D2 and the mrca of Cyanobacteria could comfortably be more than a billion years (Figure 4). Cardona et al. (2018) also showed that the photosystem existing before the duplication leading to D1 and D2 had already evolved protective mechanisms to prevent the formation of singlet oxygen, such as bicarbonatemediated redox tuning of electron transfer at the acceptor side (Figure 2) (Brinkert et al. 2016). Furthermore, our data also indicated that the span of time from the origin of photosynthesis to well past the point of duplication of D1 and D2 could be less than 200 million years. In consequence, the only way to find out how and when oxygenic photosynthesis originated is to resolve what happened during the early evolution of photochemical reaction centres, a time in the history of life that in all likelihood substantially predates the appearance of the taxonomic group that today we recognise on a 16S RNA basis as Cyanobacteria.

The second fundamental level of understanding relies on the assumption that anoxygenic reaction centres are more primitive than Photosystem II: as I discussed before, this assumption is incorrect. And all of a sudden, we find ourselves in a situation in which the fundamentals of the evolution of photosynthesis are based on unproven assumptions built on top of unproven assumptions. For instance, the idea that anoxygenic reaction centres are more primitive leads to the presupposition that primordial reaction centres did not have enough oxidising power to split water, which then makes it easy to assume that water oxidation could not be an ancestral trait. Presuppositions that have not been, in any way, validated. Now these ideas have such a strong grasp in our current understanding of the evolution of life that conceiving a highly oxidising water-splitting photosystem as the primordial photochemical ancestor, and as part of the bioenergetics toolkit of early life, becomes unthinkable (Martin and Sousa 2015) despite the absence of unequivocal data supporting otherwise.

From a paleobiological and geochemical perspective, the timing of the origin of oxygenic photosynthesis is far from settled. Rocks older than 2.5 billion years make less than 5\% of the surviving rock mass (Veizer and Mackenzie 2014). Stromatolites and bacteria-like fossils "are present throughout virtually all of the known geological record" (Schopf 2011), but anything older than 2.0 billion years cannot confidently be ascribed to any particular type of phototroph, although they have traditionally been described as "Cyanobacteria-like" (Schopf 2011, Schirrmeister et al. 2016). The record of carbon isotopes fractionation extending to the oldest sedimentary rocks is somewhat inconclusive on the matter as rubisco-derived $\delta^{13} \mathrm{C}$ signatures from anoxygenic and oxygenic phototrophs overlap. Nonetheless and as better said by Nisbet et al. (2007): "In many cases Archaean carbon isotopic results have been taken to demonstrate that the material is the product of an oxygenic biosphere (Buick 1992, Schidlowski and Aharon 1992)." Furthermore, the interpretation of redox proxies has provided estimates for the origin of oxygenic photosynthesis through the Archean and down to some of the oldest rocks more than 3.7 billion years old (Rosing and Frei 2004, Kopp et al. 2005, Holland 2006, Anbar et al. 2007, Crowe et al. 2013, Kendall et al. 2013, Lyons et al. 2014, Planavsky et al. 2014, Satkoski et al. 2015, Frei et al. 2016, Havig et al. 2017, Wang et al. 2018). Mass- 
independent fractionation of sulphur isotopes in sedimentary rock has constrained the concentration of oxygen to below $10^{-5}$ of the present atmospheric level (PAL) until about 2.4 billion years ago (Pavlov and Kasting 2002, Farquhar and Wing 2005, Zahnle et al. 2006); yet variation in the sulphur isotope record has led researchers to suggest that concentrations of oxygen likely fluctuated greatly across time and space during the Archean (Ohmoto et al. 2006, Ono et al. 2006, Wang et al. 2018). To top it all, the biogenicity, indigenousness, and syngenicity of the earliest rocks and sings of life have been strongly contested (Schopf et al. 2018). A perfect and recent example of this is the 3.7 billion years old fossilised stromatolites reported by Nutman et al. (2016) followed by a rebuttal (Allwood et al. 2018).

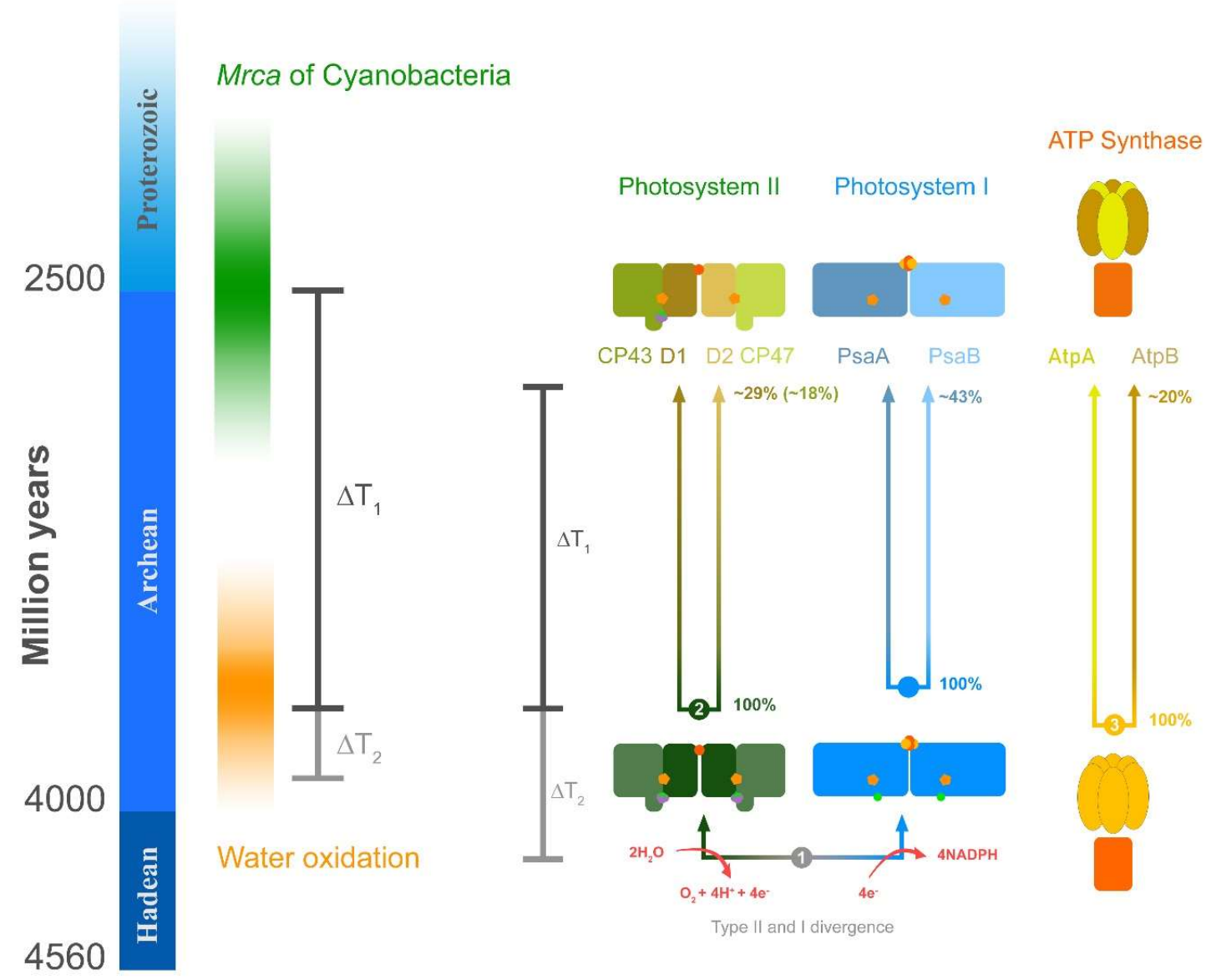

Figure 4. Schematic representation of the evolution of photosynthesis. Two key transitional points are highlighted: the divergence of Type II and Type I reaction centres, marked 1; and the duplication leading to D1 and D2, marked 2. We can then define two periods of time: one starts with the duplication of D1 and D2 and ends with the emergence of standard Photosystem II $\left(\Delta \mathrm{T}_{1}\right)$, which was inherited by the mrca of Cyanobacteria; and the other one starts with the Type II/Type I divergence and ends with the duplication of $\mathrm{D} 1$ and $\mathrm{D} 2\left(\Delta \mathrm{T}_{2}\right)$. Cardona et al. (2018) determined that $\Delta \mathrm{T}_{1}$ could comfortably be 1 billion years or more. The main reason for this is the very slow rates of evolution of Photosystem II in Cyanobacteria and photosynthetic eukaryotes. Even when $\Delta \mathrm{T}_{1}$ is 1 billion years the rate of evolution at the moment of duplication is calculated to be about 40 times greater than any rate observed in Cyanobacteria or photosynthetic eukaryotes. It also requires an exponential decrease in the rates approaching current rates before the Archean/Proterozoic transition. Furthermore, due to the exponential decrease in the rates, $\Delta \mathrm{T}_{2}$ can be well under 200 million years. It is worth comparing to the evolution of ATP synthases as both display indistinguishable evolutionary trends, both showing similar rates of evolution and a high degree of sequence conservation across distant taxa. The duplication leading to AtpA and AtpB, marked 3, is known to have occurred in the LUCA. At the moment of duplication, the sequence identity between these two was $100 \%$. Today and across all life (including Cyanobacteria), the level of sequence identity of AtpA and AtpB is about 20\%. It stands to reason that the span of time between the AtpA/AtpB duplication and the F-type ATP synthase of the $m r c a$ of Cyanobacteria is in the order of a billion years or more. In fact, an exponential decrease of the same magnitude in the rates of evolution as Photosystem II is required for that span of time to be as large. In Photosystem II the level of sequence identity between D1 and D2 is about $29 \%$ and that between $\mathrm{CP} 43$ and $\mathrm{CP} 47$ is about $18 \%$. Now, if $\Delta \mathrm{T}_{1}$ is proposed to be smaller, that would require faster rates at the 
moment of duplication than any rate reported for these types of highly conserved and very slow evolving complexes. If $\Delta \mathrm{T}_{1}$ is $100 \mathrm{Ma}$ the rate at the duplication would need to be almost 300 times greater than any observed rate: that is twice as fast as the rate of evolution of short peptide toxins of poisonous animals (Duda and Palumbi 1999), which are usually less than 20 residues long and are among the fastest evolving proteins in biology. In comparison, the "simplest" reaction centre (Gisriel et al. 2017), that of Heliobacteria, has a core protein 608 residues long. This "simplest" of reaction centres is made up of 4 interacting protein subunits, 54 (bacterio)chlorophyll pigments, two carotenoids, a $\mathrm{Fe}_{4} \mathrm{~S}_{4}$ cluster, 4 calcium ions, and a bunch of lipid molecules. Due to the structural complexity of the bioenergetics machinery, including the photosystems and ATP synthase, it is likely that they have maintained relatively slow rates of evolution across their entire evolutionary history.

What about other independent lines of evidence? Any clues? It is rather ironic that reconstructions of the proteome of the LUCA have always retrieved the core subunit of bona fide terminal oxygen reductase (Ouzounis et al. 2006, Weiss et al. 2016); a result that seems to be supported (not without controversy) by phylogenetic analysis of the same enzymes (Castresana and Moreira 1999, Brochier-Armanet et al. 2009). Let us add to the gene content of the LUCA, superoxide dismutase, rubrerythrin, and peroxiredoxin among few other oxygen-using enzymes (Zamocky et al. 2000, Ouzounis et al. 2006, Knoops et al. 2007, Slesak et al. 2012, Weiss et al. 2016). How about early evolving oxygen-tolerant hydrogenases (Pandelia et al. 2012) or cytochrome $b_{6} f$ complexes incorporating protective mechanisms against the formation of reactive oxygen species (Nitschke et al. 2010) both of which appear to substantially predate the mrca of Cyanobacteria? We cannot ignore the recent suggestion based on the physicochemical properties of amino acids that the establishment of the universal genetic code, which should predate the LUCA, required "biospheric molecular oxygen" (Granold et al. 2018). One is then forced to either dismiss the above as artefacts of one sort of another (Martin and Sousa 2015, Weiss et al. 2016): or alternatively, to accept (rather reluctantly in my personal case) that somehow the vanishingly small traces of oxygen expected from abiotic process alone, up to eight orders of magnitude below $10^{-5} \mathrm{PAL}$ (Kasting and Walker 1981), played any role at all in the early evolution of life (Castresana and Moreira 1999, Stolper et al. 2010).

If neither molecular evolution nor the geochemical record have conclusively proven that anoxygenic photosynthesis predates oxygenic photosynthesis, where does the confidence that this is the case come from? Without a doubt, it represents an historical and interpretative bias resulting from early speculation on the evolution of photosynthesis, enduring until this day and blurred into the appearance of facts by the inevitable pass of time (Blum 1937, Copeland 1938, van Niel 1949, Granick 1957, Arnon et al. 1958, Losada et al. 1960, Arnon et al. 1961, Olson 1970, Olson 1981).

Nevertheless, there is a direct and easy way to demonstrate that the idea that anoxygenic photosynthesis gave rise to oxygenic photosynthesis is based on unproven assumptions. Oxygenic photosynthesis is characterised by the use of a Type II and a Type I reaction centre linked in series. Regardless of whether these two reaction centres got together via an ancient gene duplication or via horizontal gene transfer, all proposed models for the emergence of oxygenic photosynthesis need to fulfil one major requirement. Namely, that at some point in time a transitional photosynthetic stage using an anoxygenic Type II and a Type I reaction centre was favoured over anoxygenic photosynthesis using a single reaction centre. There is absolutely no evidence that such a stage in the evolution of anoxygenic photosynthesis ever existed. There are no described anoxygenic phototrophs with genomes encoding both Type I and anoxygenic Type II reaction centre proteins. If towards the evolution of oxygenic photosynthesis such transitional stage proved advantageous over "single-reaction centre" anoxygenic photosynthesis, how come that "two-reaction centre" anoxygenic photosynthesis has not evolved several times? In theory, it would only require the transfer of a single gene from a bacterium having a homodimeric Type I reaction centre into one having a Type II. That such a type of anoxygenic photosynthesis is not more common than conventional singlereaction centre anoxygenic photosynthesis is extremely bizarre considering that horizontal transfer of photosynthesis components is supposed to be a fairly feasible process. This is even more bizarre given the assumed antiquity of anoxygenic photosynthesis (Tice and Lowe 2004, Czaja et al. 2013, Nisbet and Fowler 2014, Butterfield 2015) and the fact that most groups of anoxygenic phototrophs have cohabited in microbial mats for billions of years (Bryant and Liu 2013, Thiel et al. 2018). One could argue that there is a functional barrier preventing the acquisition and integration of a second anoxygenic photosystem. Frankly, observations from the natural world do not match the expectations derived from current models on the evolution of photosynthesis. 
There is one way out of these conundrum: that photochemical water oxidation originated before or at the divergence of Type I and Type II reaction centres.

Three basic observations from the natural world straightforwardly indicate that the origin of reaction centres was intimately linked to the origin of photochemical water oxidation. These are: 1) that oxygenic photosynthesis is the only process that exclusively uses both reaction centres, 2) that anoxygenic photosynthesis using both reaction centres does not exist, and 3) that Photosystem II, the water oxidising enzyme, is a chimeric photosystem made of a Type II core bound to a Type I antenna with both parts needed for the coordination of the $\mathrm{Mn}_{4} \mathrm{CaO}_{5}$ cluster (Cardona 2017). Taken these three observations, a better starting hypothesis in the study of evolution of photosynthesis is that the origin of photochemical reaction centres was linked to the origin of water oxidation to oxygen, rather than to the origin of a non-existent and speculative form of anoxygenic photosynthesis.

There is a fourth observation that had until recently remained unnoticed, yet it is straightforward nonetheless: that Photosystem II is the slowest evolving of all photosystems, evolving at a fifth of the rate of anoxygenic Type II reaction centres (Cardona et al. 2018), and about a third of the rate of Type I reaction centres (Cardona 2018). That means that Photosystem II is the most likely photosystem to have retained ancestral traits (Figure 1 and 2). In agreement with this, the recent structure of the homodimeric Type I reaction centre from Heliobacteria (Gisriel et al. 2017) showed a calcium bound at the electron donor site with unmistakable structural parallels to the $\mathrm{Mn}_{4} \mathrm{CaO}_{5}$ cluster of Photosystem II (Figure 1). It demonstrates that the ancestral reaction centres, before Type II and Type I, was more than well equipped for the evolution of water oxidation.

All basic ingredients required to evolve a water-oxidising photosystem were available to the very earliest forms of life: a membrane protein backbone, the capacity to make tetrapyrroles, magnesium, manganese, iron, calcium, water, and light. There is nothing peculiar about photochemical water oxidation that would unequivocally indicate that it was a late addition to the repertoire of bioenergetic reactions that sustain life. At this point therefore it should not be at all surprising that unlike the synthesis of iron-sulphur centres, thought to be the most primitive enzyme metalloclusters and usually requiring an specialised assembly machinery (Takahashi and Tokumoto 2002), the $\mathrm{Mn}_{4} \mathrm{CaO}_{5}$ cluster of Photosystem II self-assembles, both in vivo and in vitro, without the aid of assembly factors or chaperons in a process known as photoactivation (Tamura and Cheniae 1987, Miller and Brudvig 1989, Tamura et al. 1989, Bao and Burnap 2016, Zhang et al. 2017).

\section{Final words}

The study of the origin and evolution of photosynthesis has fascinated scientists for decades and will continue to capture the imagination of the scientific community and the public for decades to come. It is too soon to claim that we understand how photosynthesis originated, let alone to claim that we understand the photochemistry of the earliest reaction centres. It is too soon to ascertain that the origin of anoxygenic photosynthesis predates the origin of oxygenic photosynthesis. For the field to move forward unhindered more critical and cautions thought is required, yet the temptation to speculate will always be too sweet to resist: nonetheless, we should strive to keep the lines between assumptions, hypotheses, predictions and facts well delimited. Only then we can lay new foundations upon which to build a modern framework for the study of the evolution of photosynthesis.

\section{Acknowledgements}

The financial support of the Leverhulme Trust (grant RPG-2017-223) is gracefully acknowledged.

\section{References}

Allen, J. F. (2003). "The function of genomes in bioenergetic organelles." Philos Trans R Soc Lond B Biol Sci 358(1429): 19-37; discussion 37-18. DOI: 10.1098/rstb.2002.1191.

Allen, J. F. (2005). "A redox switch hypothesis for the origin of two light reactions in photosynthesis." FEBS Lett 579(5): 963-968. DOI: DOI 10.1016/j.febslet.2005.01.015.

Allwood, A. C., M. T. Rosing, D. T. Flannery, J. A. Hurowitz and C. M. Heirwegh (2018). "Reassessing evidence of life in 3,700-million-year-old rocks of Greenland." Nature 563(7730): 241-244. DOI: 10.1038/s41586-018-0610-4.

Anbar, A. D., Y. Duan, T. W. Lyons, G. L. Arnold, B. Kendall, R. A. Creaser, A. J. Kaufman, G. W. Gordon, C. Scott, J. Garvin and R. Buick (2007). "A whiff of oxygen before the great oxidation event?" Science 317(5846): 1903-1906. DOI: $10.1126 /$ science. 1140325 . 
Arnon, D. I., M. Losada, M. Nozaki and K. Tagawa (1961). "Photoproduction of hydrogen, photofixation of nitrogen and a unified concept of photosynthesis." Nature 190: 601-606.

Arnon, D. I., F. R. Whatley and M. B. Allen (1958). "Assimilatory Power in Photosynthesis: Photosynthetic phosphorylation by isolated chloroplasts is coupled with TPN reduction." Science 127(3305): 1026-1034. DOI: 10.1126/science.127.3305.1026.

Bao, H. and R. L. Burnap (2016). "Photoactivation: The Light-Driven Assembly of the Water Oxidation Complex of Photosystem II." Front Plant Sci 7. DOI: 10.3389/fpls.2016.00578.

Beanland, T. J. (1990). "Evolutionary relationships between Q-Type photosynthetic reaction centers - Hypothesis-testing using parsimony." J Theor Biol 145(4): 535-545. DOI: Doi 10.1016/S0022-5193(05)80487-4.

Ben-Shem, A., F. Frolow and N. Nelson (2004). "Evolution of photosystem I - from symmetry through pseudosymmetry to asymmetry." FEBS Lett 564(3): 274-280. DOI: 10.1016/S0014-5793(04)00360-6.

Betts, H. C., M. N. Puttick, J. W. Clark, T. A. Williams, P. C. J. Donoghue and D. Pisani (2018). "Integrated genomic and fossil evidence illuminates life's early evolution and eukaryote origin." Nature Ecology \& Evolution. DOI: 10.1038/s41559-018-0644-x.

Blankenship, R. E., D. C. Brune and J. C. Olson (2018). "Remembering John M. Olson (1929-2017)." Photosynthesis research 137(2): 161-169. DOI: 10.1007/s11120-018-0489-9.

Blum, H. F. (1937). "On the Evolution of Photosynthesis." The American Naturalist 71: 350-362 DOI: https://doi.org/10.1086/280723.

Brinkert, K., S. De Causmaecker, A. Krieger-Liszkay, A. Fantuzzi and A. W. Rutherford (2016). "Bicarbonate-induced redox tuning in Photosystem II for regulation and protection." Proc Natl Acad Sci USA 113(43): 12144-12149. DOI: 10.1073/pnas.1608862113.

Brinkmann, H., M. Goker, M. Koblizek, I. Wagner-Dobler and J. Petersen (2018). "Horizontal operon transfer, plasmids, and the evolution of photosynthesis in Rhodobacteraceae." Isme J 12(8): 1994-2010. DOI: 10.1038/s41396-018-0150-9.

Brochier-Armanet, C., E. Talla and S. Gribaldo (2009). "The multiple evolutionary histories of dioxygen reductases: Implications for the origin and evolution of aerobic respiration." Molecular biology and evolution 26(2): 285-297. DOI: $10.1093 / \mathrm{molbev} / \mathrm{msn} 246$.

Bryant, D., Z. Liu, T. LI, F. Zhao, C. G. Klatt, D. Ward, N. U. Frigaard and J. Overmann (2012). Comparative and functional genomics of anoxygenic green bacteria from the taxa Chlorobi, Chloroflexi, and Acidobacteria. Functional Genomics and Evolution of Photosynthetic Systems. R. L. Burnap and W. Vermaas. Dordrecht Springer. 33: 47-102.

Bryant, D. A., A. M. G. Costas, J. A. Maresca, A. G. M. Chew, C. G. Klatt, M. M. Bateson, L. J. Tallon, J. Hostetler, W. C. Nelson, J. F. Heidelberg and D. M. Ward (2007). "Candidatus Chloracidobacterium thermophilum: An aerobic phototrophic acidobacterium." Science 317(5837): 523-526. DOI: 10.1126/science.1143236.

Bryant, D. A. and Z. F. Liu (2013). "Green Bacteria: Insights into Green Bacterial Evolution through Genomic Analyses." Adv Bot Res 66: 99-150. DOI: Doi 10.1016/B978-0-12-397923-0.00004-7.

Buick, R. (1992). "The Antiquity of Oxygenic Photosynthesis - Evidence from Stromatolites in Sulfate-Deficient Archean Lakes." Science 255(5040): 74-77. DOI: DOI 10.1126/science.11536492.

Butterfield, N. J. (2015). "Proterozoic photosynthesis - a critical review." Palaeontology 58(6): 953-972. DOI: 10.1111/pala.12211.

Cardona, T. (2015). "A fresh look at the evolution and diversification of photochemical reaction centers." Photosynthesis research 126(1): 111-134. DOI: 10.1007/s11120-014-0065-x.

Cardona, T. (2016). "Reconstructing the origin of oxygenic photosynthesis: Do assembly and photoactivation recapitulate evolution?" Front Plant Sci 7: 257. DOI: 10.3389/fpls.2016.00257.

Cardona, T. (2017). "Photosystem II is a chimera of reaction centers." J Mol Evol 84(2-3): 149-151. DOI: 10.1007/s00239017-9784-x.

Cardona, T. (2018). "Early Archean origin of heterodimeric Photosystem I." Heliyon 4(3): e00548. DOI: 10.1016/j.heliyon.2018.e00548.

Cardona, T., J. W. Murray and A. W. Rutherford (2015). "Origin and evolution of water oxidation before the last common ancestor of the Cyanobacteria." Mol Biol Evol 32(5): 1310-1328. DOI: DOI 10.1093/molbev/msv024.

Cardona, T., P. Sanchez-Baracaldo, A. W. Rutherford and A. W. D. Larkum (2018). "Early Archean origin of Photosystem II." Geobiology. DOI: 10.1111/gbi.12322.

Cardona, T., A. Sedoud, N. Cox and A. W. Rutherford (2012). "Charge separation in Photosystem II: A comparative and evolutionary overview." Biochimica et Biophysica Acta (BBA) - Bioenergetics 1817(1): 26-43. DOI: DOI 10.1016/j.bbabio.2011.07.012.

Castresana, J. and D. Moreira (1999). "Respiratory chains in the last common ancestor of living organisms." J Mol Evol 49(4): 453-460. DOI: Doi 10.1007/P100006568.

Ciccarelli, F. D., T. Doerks, C. von Mering, C. J. Creevey, B. Snel and P. Bork (2006). "Toward automatic reconstruction of a highly resolved tree of life." Science 311(5765): 1283-1287. DOI: 10.1126/science.1123061.

Copeland, H. F. (1938). "The kingdoms of organisms." The quarterly review of biology 13: 383-420. DOI: https://doi.org/10.1086/394568.

Cornejo-Castillo, F. M., A. M. Cabello, G. Salazar, P. Sanchez-Baracaldo, G. Lima-Mendez, P. Hingamp, A. Alberti, S. Sunagawa, P. Bork, C. de Vargas, J. Raes, C. Bowler, P. Wincker, J. P. Zehr, J. M. Gasol, R. Massana and S. G. Acinas (2016). "Cyanobacterial symbionts diverged in the late Cretaceous towards lineage-specific nitrogen fixation factories in single-celled phytoplankton." Nature communications 7. DOI: 10.1038/ncomms 11071.

Crowe, S. A., L. N. Dossing, N. J. Beukes, M. Bau, S. J. Kruger, R. Frei and D. E. Canfield (2013). "Atmospheric oxygenation three billion years ago." Nature 501(7468): 535-538. DOI: 10.1038/nature12426.

Cser, K. and I. Vass (2007). "Radiative and non-radiative charge recombination pathways in Photosystem II studied by thermoluminescence and chlorophyll fluorescence in the cyanobacterium Synechocystis 6803." Bba-Bioenergetics 1767(3): 233-243. DOI: DOI 10.1016/j.bbabio.2007.01.022. 
Czaja, A. D., C. M. Johnson, B. L. Beard, E. E. Roden, W. Q. Li and S. Moorbath (2013). "Biological Fe oxidation controlled deposition of banded iron formation in the ca. 3770 Ma Isua Supracrustal Belt (West Greenland)." Earth and Planetary Science Letters 363: 192-203. DOI: 10.1016/j.epsl.2012.12.025.

David, L. A. and E. J. Alm (2011). "Rapid evolutionary innovation during an Archaean genetic expansion." Nature 469(7328): 93-96. DOI: 10.1038/Nature09649.

Duda, T. F., Jr. and S. R. Palumbi (1999). "Molecular genetics of ecological diversification: duplication and rapid evolution of toxin genes of the venomous gastropod Conus." P Natl Acad Sci USA 96(12): 6820-6823.

Falcon, L. I., S. Magallon and A. Castillo (2010). "Dating the cyanobacterial ancestor of the chloroplast." Isme J 4(6): 777 783. DOI: 10.1038 /ismej.2010.2.

Farquhar, J. and B. A. Wing (2005). "The terrestrial record of stable sulphur isotopes: a review of the implications for evolution of Earth's sulphur cycle." Geol Soc Spec Publ 248: 167-177. DOI: Doi 10.1144/Gsl.Sp.2005.248.01.09.

Fischer, W. W., J. Hemp and J. E. Johnson (2016). "Evolution of oxygenic photosynthesis." Annu Rev Earth Planet Sci 44: 647-683. DOI: 10.1146/annurev-earth-060313-054810.

Frei, R., S. A. Crowe, M. Bau, A. Polat, D. A. Fowle and L. N. Døssing (2016). "Oxidative elemental cycling under the low $\mathrm{O}_{2}$ Eoarchean atmosphere." Sci Rep 6: 21058. DOI: 10.1038/srep21058.

Gisriel, C., I. Sarrou, B. Ferlez, J. H. Golbeck, K. E. Redding and R. Fromme (2017). "Structure of a symmetric photosynthetic reaction center-photosystem." Science 357(6355): 1021-1025. DOI: 10.1126/science.aan5611.

Gogarten, J. P., H. Kibak, P. Dittrich, L. Taiz, E. J. Bowman, B. J. Bowman, M. F. Manolson, R. J. Poole, T. Date, T. Oshima, J. Konishi, K. Denda and M. Yoshida (1989). "Evolution of the Vacuolar H+-Atpase - Implications for the Origin of Eukaryotes." Proceedings of the National Academy of Sciences of the United States of America 86(17): 6661-6665. DOI: DOI 10.1073/pnas.86.17.6661.

Gould, S. B., R. R. Waller and G. I. McFadden (2008). "Plastid evolution." Annual review of plant biology 59: 491-517. DOI: DOI 10.1146/annurev.arplant.59.032607.092915.

Granick, S. (1957). "Speculations on the origins and evolution of photosynthesis." Ann N Y Acad Sci 69(2): 292-308.

Granold, M., P. Hajieva, M. I. Tosa, F. D. Irimie and B. Moosmann (2018). "Modern diversification of the amino acid repertoire driven by oxygen." P Natl Acad Sci USA 115(1): 41-46. DOI: 10.1073/pnas.1717100115.

Grossmann, L., C. Bock, M. Schweikert and J. Boenigk (2016). "Small but Manifold - Hidden Diversity in "Spumella-like Flagellates"." J Eukaryot Microbiol 63(4): 419-439. DOI: 10.1111/jeu.12287.

Havig, J. R., T. L. Hamilton, A. Bachan and L. R. Kump (2017). "Sulfur and carbon isotopic evidence for metabolic pathway evolution and a four-stepped Earth system progression across the Archean and Paleoproterozoic." Earth-Sci Rev 174: 1-21. DOI: https://doi.org/10.1016/j.earscirev.2017.06.014.

Ho, M. Y., N. T. Soulier, D. P. Canniffe, G. Z. Shen and D. A. Bryant (2017). "Light regulation of pigment and photosystem biosynthesis in cyanobacteria." Curr Opin Plant Biol 37: 24-33. DOI: 10.1016/j.pbi.2017.03.006.

Hohmann-Marriott, M. F. and R. E. Blankenship (2008). Anoxygenic Type-I photosystems and evolution of photosynthetic reaction centers. Photosynthetic Protein Complexes. P. Fromme, Wiley-VCH Verlag GmbH \& Co. KGaA: 295-324.

Hohmann-Marriott, M. F. and R. E. Blankenship (2011). "Evolution of photosynthesis." Annu Rev Plant Biol 62: 515-548. DOI: 10.1146/annurev-arplant-042110-103811.

Holland, H. D. (2006). "The oxygenation of the atmosphere and oceans." Philos T R Soc B 361(1470): 903-915. DOI: DOI 10.1098/rstb.2006.1838.

Hug, L. A., B. J. Baker, K. Anantharaman, C. T. Brown, A. J. Probst, C. J. Castelle, C. N. Butterfield, A. W. Hernsdorf, Y. Amano, K. Ise, Y. Suzuki, N. Dudek, D. A. Relman, K. M. Finstad, R. Amundson, B. C. Thomas and J. F. Banfield (2016). "A new view of the tree of life." Nat Microbiol 1: 16048. DOI: 10.1038/nmicrobiol.2016.48.

Jun, S. R., G. E. Sims, G. H. A. Wu and S. H. Kim (2010). "Whole-proteome phylogeny of prokaryotes by feature frequency profiles: An alignment-free method with optimal feature resolution." Proceedings of the National Academy of Sciences of the United States of America 107(1): 133-138. DOI: DOI 10.1073/pnas.0913033107.

Kasting, J. F. and J. C. G. Walker (1981). "Limits on Oxygen Concentration in the Prebiological Atmosphere and the Rate of Abiotic Fixation of Nitrogen." J Geophys Res-Oc Atm 86(Nc2): 1147-1158. DOI: DOI 10.1029/JC086iC02p01147.

Kendall, B., G. A. Brennecka, S. Weyer and A. D. Anbar (2013). "Uranium isotope fractionation suggests oxidative uranium mobilization at 2.50 Ga." Chem Geol 362: 105-114. DOI: 10.1016/j.chemgeo.2013.08.010.

Knoops, B., E. Loumaye and V. Van Der Eecken (2007). "Evolution of the peroxiredoxins." Subcell Biochem 44: 27-40.

Kopp, R. E., J. L. Kirschvink, I. A. Hilburn and C. Z. Nash (2005). "The Paleoproterozoic snowball Earth: a climate disaster triggered by the evolution of oxygenic photosynthesis." Proceedings of the National Academy of Sciences of the United States of America 102(32): 11131-11136. DOI: 10.1073/pnas.0504878102.

Losada, M., A. V. Trebst, S. Ogata and D. I. Arnon (1960). "Equivalence of light and adenosine triphosphate in bacterial photosynthesis." Nature 186: 753-760.

Louca, S., P. M. Shih, M. W. Pennell, W. W. Fischer, L. W. Parfrey and M. Doebeli (2018). "Bacterial diversification through geological time." Nature Ecology \& Evolution 2(9): 1458-1467. DOI: 10.1038/s41559-018-0625-0.

Lyons, T. W., C. T. Reinhard and N. J. Planavsky (2014). "The rise of oxygen in Earth's early ocean and atmosphere." Nature 506(7488): 307-315. DOI: $10.1038 /$ nature13068.

Magnabosco, C., K. R. Moore, J. M. Wolfe and G. P. Fournier (2018). "Dating phototropic microbial lineages with reticulate gene histories." Geobiology. DOI: 10.1111/gbi.12273.

Marin, J., F. U. Battistuzzi, A. C. Brown and S. B. Hedges (2017). "The timetree of prokaryotes: New insights into their evolution and speciation." Mol Biol Evol 34: 437-446. DOI: 10.1093/molbev/msw245.

Martin, W., T. Rujan, E. Richly, A. Hansen, S. Cornelsen, T. Lins, D. Leister, B. Stoebe, M. Hasegawa and D. Penny (2002). "Evolutionary analysis of Arabidopsis, cyanobacterial, and chloroplast genomes reveals plastid phylogeny and thousands of cyanobacterial genes in the nucleus." Proceedings of the National Academy of Sciences of the United States of America 99(19): 12246-12251. DOI: 10.1073/pnas.182432999. 
Martin, W. F., D. A. Bryant and J. T. Beatty (2018). "A physiological perspective on the origin and evolution of photosynthesis." Fems Microbiol Rev 42(2): 205-231. DOI: 10.1093/femsre/fux056.

Martin, W. F. and F. L. Sousa (2015). "Early Microbial Evolution: The Age of Anaerobes." Cold Spring Harb Perspect Biol 8(2): a018127. DOI: $10.1101 /$ cshperspect.a018127.

Miller, A. F. and G. W. Brudvig (1989). "Manganese and Calcium Requirements for Reconstitution of Oxygen-Evolution Activity in Manganese-Depleted Photosystem-Ii Membranes." Biochemistry 28(20): 8181-8190. DOI: DOI 10.1021/bi00446a033.

Mix, L. J., D. Haig and C. M. Cavanaugh (2005). "Phylogenetic analyses of the core antenna domain: Investigating the origin of photosystem I." J Mol Evol 60(2): 153-163. DOI: DOI 10.1007/s00239-003-0181-2.

Moore, R. B., M. Obornik, J. Janouskovec, T. Chrudimsky, M. Vancova, D. H. Green, S. W. Wright, N. W. Davies, C. J. Bolch, K. Heimann, J. Slapeta, O. Hoegh-Guldberg, J. M. Logsdon and D. A. Carter (2008). "A photosynthetic alveolate closely related to apicomplexan parasites." Nature 451(7181): 959-963. DOI: 10.1038/nature06635.

Mulkidjanian, A. Y., E. V. Koonin, K. S. Makarova, S. L. Mekhedov, A. Sorokin, Y. I. Wolf, A. Dufresne, F. Partensky, H. Burd, D. Kaznadzey, R. Haselkorn and M. Y. Galperin (2006). "The cyanobacterial genome core and the origin of photosynthesis." Proceedings of the National Academy of Sciences of the United States of America 103(35): 1312613131. DOI: DOI 10.1073/pnas.0605709103.

Mulkidjanian, A. Y., K. S. Makarova, M. Y. Galperin and E. V. Koonin (2007). "Inventing the dynamo machine: the evolution of the F-type and V-type ATPases." Nat Rev Microbiol 5(11): 892-899. DOI: 10.1038/nrmicro1767.

Nakayama, T., R. Kamikawa, G. Tanifuji, Y. Kashiyama, N. Ohkouchi, J. M. Archibald and Y. Inagaki (2014). "Complete genome of a nonphotosynthetic cyanobacterium in a diatom reveals recent adaptations to an intracellular lifestyle." $\mathrm{P}$ Natl Acad Sci USA 111(31): 11407-11412. DOI: 10.1073/pnas.1405222111.

Nickelsen, J. and B. Rengstl (2013). "Photosystem II assembly: From cyanobacteria to plants." Annu Rev Plant Biol 64: 609635. DOI: 10.1146/annurev-arplant-050312-120124.

Nisbet, E. G. and C. F. R. Fowler (2014). The early history of life. Treatise on Geochemistry. K. D. M. and W. H. Schlesinger. Amsterdam, Elsevier Science. 10: 1-42.

Nisbet, E. G., N. V. Grassineau, C. J. Howe, P. I. Abell, M. Regelous and R. E. R. Nisbet (2007). "The age of Rubisco: the evolution of oxygenic photosynthesis." Geobiology 5(4): 311-335. DOI: 10.1111/j.1472-4669.2007.00127.x.

Nitschke, W., R. van Lis, B. Schoepp-Cothenet and F. Baymann (2010). "The "green" phylogenetic clade of Rieske/cytb complexes." Photosynthesis research 104(2-3): 347-355. DOI: 10.1007/s11120-010-9532-1.

Nixon, P. J., F. Michoux, J. F. Yu, M. Boehm and J. Komenda (2010). "Recent advances in understanding the assembly and repair of Photosystem II." Ann Bot 106(1): 1-16. DOI: Doi 10.1093/Aob/Mcq059.

Nurnberg, D. J., J. Morton, S. Santabarbara, A. Telfer, P. Joliot, L. A. Antonaru, A. V. Ruban, T. Cardona, E. Krausz, A. Boussac, A. Fantuzzi and A. W. Rutherford (2018). "Photochemistry beyond the red limit in chlorophyll f-containing photosystems." Science 360(6394): 1210-1213. DOI: 10.1126/science.aar8313.

Nutman, A. P., V. C. Bennett, C. R. Friend, M. J. Van Kranendonk and A. R. Chivas (2016). "Rapid emergence of life shown by discovery of 3,700-million-year-old microbial structures." Nature 537(7621): 535-538. DOI: 10.1038/nature 19355.

Ohmoto, H., Y. Watanabe, H. Ikemi, S. R. Poulson and B. E. Taylor (2006). "Sulphur isotope evidence for an oxic Archaean atmosphere." Nature 442(7105): 908-911. DOI: 10.1038/nature05044.

Olson, J. M. (1970). "The evolution of photosynthesis." Science 168(3930): 438-446.

Olson, J. M. (1981). "Evolution of photosynthetic reaction centers." Biosystems 14(1): 89-94.

Olson, J. M. and R. E. Blankenship (2004). "Thinking about the evolution of photosynthesis." Photosynthesis Res 80(1-3): 373-386. DOI: Doi 10.1023/B:Pres.0000030457.06495.83.

Ono, S., N. J. Beukes, D. Rumble and M. L. Fogel (2006). "Early evolution of atmospheric oxygen from multiple-sulfur and carbon isotope records of the 2.9 Ga Mozaan Group of the Pongola Supergroup, Southern Africa." S Afr J Geol 109(12): 97-108. DOI: DOI 10.2113/gssajg.109.1-2.97.

Orf, G. S., C. Gisriel and K. E. Redding (2018). "Evolution of photosynthetic reaction centers: insights from the structure of the heliobacterial reaction center." Photosynthesis research. DOI: 10.1007/s11120-018-0503-2.

Ouzounis, C. A., V. Kunin, N. Darzentas and L. Goldovsky (2006). "A minimal estimate for the gene content of the last universal common ancestor - exobiology from a terrestrial perspective." Res Microbiol 157(1): 57-68. DOI: 10.1016/j.resmic.2005.06.015.

Pandelia, M. E., W. Lubitz and W. Nitschke (2012). "Evolution and diversification of Group 1 [NiFe] hydrogenases. Is there a phylogenetic marker for $\mathrm{O}_{2}$-tolerance?" Biochimica et biophysica acta 1817(9): 1565-1575. DOI: 10.1016/j.bbabio.2012.04.012.

Pavlov, A. A. and J. F. Kasting (2002). "Mass-independent fractionation of sulfur isotopes in Archean sediments: Strong evidence for an anoxic Archean atmosphere." Astrobiology 2(1): 27-41. DOI: Doi 10.1089/153110702753621321.

Planavsky, N. J., D. Asael, A. Hofmann, C. T. Reinhard, S. V. Lalonde, A. Knudsen, X. Wang, F. Ossa Ossa, E. Pecoits, A. J. B. Smith, N. J. Beukes, A. Bekker, T. M. Johnson, K. O. Konhauser, T. W. Lyons and O. J. Rouxel (2014). "Evidence for oxygenic photosynthesis half a billion years before the Great Oxidation Event." Nat Geosci 7(4): 283-286. DOI: $10.1038 /$ ngeo2 122 .

Ravin, N. V., E. V. Gruzdev, A. V. Beletsky, A. M. Mazur, E. B. Prokhortchouk, M. A. Filyushin, E. Z. Kochieva, V. V. Kadnikov, A. V. Mardanov and K. G. Skryabin (2016). "The loss of photosynthetic pathways in the plastid and nuclear genomes of the non-photosynthetic mycoheterotrophic eudicot Monotropa hypopitys." BMC Plant Biol 16(Suppl 3): 238. DOI: $10.1186 / \mathrm{s} 12870-016-0929-7$.

Raymond, J. (2009). "The role of horizontal gene transfer in photosynthesis, oxygen production, and oxygen tolerance." Methods Mol Biol 532: 323-338. DOI: 10.1007/978-1-60327-853-9_19.

Rosing, M. T. and R. Frei (2004). "U-rich Archaean sea-floor sediments from Greenland - indications of $>3700$ Ma oxygenic photosynthesis." Earth and Planetary Science Letters 217(3-4): 237-244. DOI: 10.1016/S0012-821x(03)00609-5. 
Rutherford, A. W. and P. Faller (2003). "Photosystem II: evolutionary perspectives." Philos T R Soc B 358(1429): 245-253. DOI: DOI 10.1098/rstb.2002.1186.

Rutherford, A. W., T. Mattioli and W. Nitschke (1996). The FeS-type photosystems and the evolution of photosynthetic reaction centers. Origin and evolution of biological energy conversion. H. Baltscheffsky. New York, N. Y., VCH: 177203.

Rutherford, A. W. and W. Nitschke (1996). Photosystem II and the quinone-iron-containing reaction centers. Origin and evolution of biological energy conversion. H. Baltscheffsky. New York, N. Y., VCH: 143-175.

Rutherford, A. W., A. Osyczka and F. Rappaport (2012). "Back-reactions, short-circuits, leaks and other energy wasteful reactions in biological electron transfer: redox tuning to survive life in $\mathrm{O}_{2}$." FEBS Lett 586(5): 603-616. DOI: 10.1016/j.febslet.2011.12.039.

Saldarriaga, J. F., F. J. Taylor, P. J. Keeling and T. Cavalier-Smith (2001). "Dinoflagellate nuclear SSU rRNA phylogeny suggests multiple plastid losses and replacements." J Mol Evol 53(3): 204-213. DOI: 10.1007/s002390010210.

Sanchez-Baracaldo, P., J. A. Raven, D. Pisani and A. H. Knoll (2017). "Early photosynthetic eukaryotes inhabited low-salinity habitats." Proc Natl Acad Sci USA. DOI: 10.1073/pnas.1620089114.

Satkoski, A. M., N. J. Beukes, W. Li, B. L. Beard and C. M. Johnson (2015). "A redox-stratified ocean 3.2 billion years ago." Earth and Planetary Science Letters 430: 43-53.

Schidlowski, M. and P. Aharon (1992). Carbon Cycle and Carbon Isotope Record: Geochemical Impact of Life over $3.8 \mathrm{Ga}$ of Earth History. Early Organic Evolution: Implications for Mineral and Energy Resources. M. Schidlowski, S. Golubic, M. M. Kimberley, D. M. McKirdy and P. A. Trudinger. Berlin, Heidelberg, Springer Berlin Heidelberg: 147-175.

Schirrmeister, B. E., P. Sanchez-Baracaldo and D. Wacey (2016). "Cyanobacterial evolution during the Precambrian." International Journal of Astrobiology 15(3): 187-204. DOI: 10.1017/S1473550415000579.

Schopf, J. W. (2011). "The paleobiological record of photosynthesis." Photosynthesis Res 107(1): 87-101. DOI: DOI $10.1007 / \mathrm{s} 11120-010-9577-1$.

Schopf, J. W., K. Kitajima, M. J. Spicuzza, A. B. Kudryavtsev and J. W. Valley (2018). "SIMS analyses of the oldest known assemblage of microfossils document their taxon-correlated carbon isotope compositions." P Natl Acad Sci USA 115(1): 53-58. DOI: 10.1073/pnas.1718063115.

Segata, N., D. Bornigen, X. C. Morgan and C. Huttenhower (2013). "PhyloPhlAn is a new method for improved phylogenetic and taxonomic placement of microbes." Nature communications 4. DOI: Doi 10.1038/Ncomms3304.

Sereno, P. C. (1999). "The evolution of dinosaurs." Science 284(5423): 2137-2147. DOI: DOI 10.1126/science.284.5423.2137.

Shi, T., T. S. Bibby, L. Jiang, A. J. Irwin and P. G. Falkowski (2005). "Protein interactions limit the rate of evolution of photosynthetic genes in cyanobacteria." Mol Biol Evol 22(11): 2179-2189. DOI: 10.1093/molbev/msi216.

Shih, P. M., J. Hemp, L. M. Ward, N. J. Matzke and W. W. Fischer (2017). "Crown group Oxyphotobacteria postdate the rise of oxygen." Geobiology 15(1): 19-29. DOI: 10.1111/gbi.12200.

Shih, P. M., L. M. Ward and W. W. Fischer (2017). "Evolution of the 3-hydroxypropionate bicycle and recent transfer of anoxygenic photosynthesis into the Chloroflexi." P Natl Acad Sci USA 114(40): 10749-10754. DOI: $10.1073 /$ pnas.1710798114.

Slesak, I., H. Slesak and J. Kruk (2012). "Oxygen and Hydrogen Peroxide in the Early Evolution of Life on Earth: In silico Comparative Analysis of Biochemical Pathways." Astrobiology 12(8): 775-784. DOI: 10.1089/ast.2011.0704.

Smith, D. R. and R. W. Lee (2014). "A Plastid without a Genome: Evidence from the Nonphotosynthetic Green Algal Genus Polytomella." Plant Physiol 164(4): 1812-1819. DOI: 10.1104/pp.113.233718.

Soo, R. M., J. Hemp, D. H. Parks, W. W. Fischer and P. Hugenholtz (2017). "On the origins of oxygenic photosynthesis and aerobic respiration in Cyanobacteria." Science 355(6332): 1436-1440. DOI: 10.1126/science.aal3794.

Soo, R. M., C. T. Skennerton, Y. Sekiguchi, M. Imelfort, S. J. Paech, P. G. Dennis, J. A. Steen, D. H. Parks, G. W. Tyson and P. Hugenholtz (2014). "An expanded genomic representation of the phylum Cyanobacteria." Genome biology and evolution 6(5): 1031-1045. DOI: 10.1093/Gbe/Evu073.

Sousa, F. L., L. Shavit-Grievink, J. F. Allen and W. F. Martin (2013). "Chlorophyll biosynthesis gene evolution indicates photosystem gene duplication, not photosystem merger, at the origin of oxygenic photosynthesis." Genome biology and evolution 5(1): 200-216. DOI: 10.1093/Gbe/Evs127.

Stolper, D. A., N. P. Revsbech and D. E. Canfield (2010). "Aerobic growth at nanomolar oxygen concentrations." Proceedings of the National Academy of Sciences of the United States of America 107(44): 18755-18760. DOI: 10.1073/pnas.1013435107.

Sugiura, M., C. Azami, K. Koyama, A. W. Rutherford, F. Rappaport and A. Boussac (2013). "Modification of the pheophytin redox potential in Thermosynechococcus elongatus Photosystem II with PsbA3 as D1." Biochimica et biophysica acta 1837(1): 139-148. DOI: 10.1016/j.bbabio.2013.09.009.

Suzuki, S., R. Endoh, R. Manabe, M. Ohkuma and Y. Hirakawa (2018). "Multiple losses of photosynthesis and convergent reductive genome evolution in the colourless green algae Prototheca." Sci Rep 8. DOI: 10.1038/s41598-017-18378-8.

Swingley, W. D., R. E. Blankenship and J. Raymond (2008). Insight into cyanobacterial evolution from comparative genomics. The cyanobacteria: molecular biology, gnetics and evolution. A. Herrero and E. Flores. Norfolk, Caister Academic Press: 24-44.

Takahashi, Y. and U. Tokumoto (2002). "A third bacterial system for the assembly of iron-sulfur clusters with homologs in archaea and plastids." J Biol Chem 277(32): 28380-28383. DOI: 10.1074/jbc.C200365200.

Tamura, N. and G. Cheniae (1987). "Photoactivation of the Water-Oxidizing Complex in Photosystem-Ii Membranes Depleted of Mn and Extrinsic Proteins .1. Biochemical and Kinetic Characterization." Biochimica et biophysica acta 890(2): 179-194. DOI: Doi 10.1016/0005-2728(87)90019-3.

Tamura, N., Y. Inoue and G. M. Cheniae (1989). "Photoactivation of the Water-Oxidizing Complex in Photosystem-Ii Membranes Depleted of Mn, Ca and Extrinsic Proteins .2. Studies on the Functions of Ca-2+." Biochimica et biophysica acta 976(2-3): 173-181. DOI: Doi 10.1016/S0005-2728(89)80227-0. 
Thiel, V., M. Tank and D. A. Bryant (2018). "Diversity of Chlorophototrophic Bacteria Revealed in the Omics Era." Annual review of plant biology. DOI: 10.1146/annurev-arplant-042817-040500.

Thompson, A. W., R. A. Foster, A. Krupke, B. J. Carter, N. Musat, D. Vaulot, M. M. M. Kuypers and J. P. Zehr (2012). "Unicellular cyanobacterium symbiotic with a single-celled eukaryotic alga." Science 337(6101): 1546-1550. DOI: $10.1126 /$ science. 1222700 .

Tice, M. M. and D. R. Lowe (2004). "Photosynthetic microbial mats in the 3,416-Myr-old ocean." Nature 431(7008): 549552. DOI: $10.1038 /$ nature 02888 .

van Niel, C. B. (1949). "The comparative biochemistry of photosynthesis." Am Sci 37(3): 371-383.

Veizer, J. and F. T. Mackenzie (2014). 9.15 - Evolution of Sedimentary Rocks. Treatise on Geochemistry (Second Edition). H. D. Holland and K. K. Turekian. Oxford, Elsevier: 399-435.

Vinyard, D. J. and G. W. Brudvig (2017). "Progress Toward a Molecular Mechanism of Water Oxidation in Photosystem II." Annu Rev Phys Chem 68: 101-116. DOI: 10.1146/annurev-physchem-052516-044820.

Wang, X. L., N. J. Planavsky, A. Hofmann, E. E. Saupe, B. P. De Corte, P. Philippot, S. V. LaLonde, N. E. Jemison, H. J. Zou, F. O. Ossa, K. Rybacki, N. Alfimova, M. J. Larson, H. Tsikos, P. W. Fralick, T. M. Johnson, A. C. Knudsen, C. T. Reinhard and K. O. Konhauser (2018). "A Mesoarchean shift in uranium isotope systematics." Geochim Cosmochim Ac 238: 438-452. DOI: 10.1016/j.gca.2018.07.024.

Ward, L. M., J. Hemp, P. M. Shih, S. E. McGlynn and W. W. Fischer (2018). "Evolution of Phototrophy in the Chloroflexi Phylum Driven by Horizontal Gene Transfer." Frontiers in microbiology 9. DOI: 10.3389/fmicb.2018.00260.

Weiss, M. C., F. L. Sousa, N. Mrnjavac, S. Neukirchen, M. Roettger, S. Nelson-Sathi and W. F. Martin (2016). "The physiology and habitat of the last universal common ancestor." Nat Microbiol 1(9): 16116. DOI: 10.1038/nmicrobiol.2016.116.

Westwood, J. H., J. I. Yoder, M. P. Timko and C. W. dePamphilis (2010). "The evolution of parasitism in plants." Trends in plant science 15(4): 227-235. DOI: 10.1016/j.tplants.2010.01.004.

Xu, X., X. T. Zheng and H. L. You (2009). "A new feather type in a nonavian theropod and the early evolution of feathers." Proceedings of the National Academy of Sciences of the United States of America 106(3): 832-834. DOI: 10.1073/pnas.0810055106.

Zahnle, K., M. Claire and D. Catling (2006). "The loss of mass-independent fractionation in sulfur due to a Palaeoproterozoic collapse of atmospheric methane." Geobiology 4(4): 271-283. DOI: 10.1111/j.1472-4669.2006.00085.x.

Zamocky, M., S. Janecek and F. Koller (2000). "Common phylogeny of catalase-peroxidases and ascorbate peroxidases." Gene 256(1-2): 169-182. DOI: 10.1016/S0378-1119(00)00358-9.

Zeng, Y. H., F. Y. Feng, H. Medova, J. Dean and M. Koblizek (2014). "Functional Type 2 photosynthetic reaction centers found in the rare bacterial phylum Gemmatimonadetes." Proceedings of the National Academy of Sciences of the United States of America 111(21): 7795-7800. DOI: DOI 10.1073/pnas.1400295111.

Zhang, M., M. Bommer, R. Chatterjee, R. Hussein, J. Yano, H. Dau, J. Kern, H. Dobbek and A. Zouni (2017). "Structural insights into the light-driven auto-assembly process of the water oxidizing Mn4CaO5-cluster in photosystem II." Elife 6. DOI: $10.7554 /$ eLife.26933. 